\title{
SITUAÇÃO DA ARBORIZAÇÃO URBANA NO MUNICÍPIO DE FREDERICO WESTPHALEN, RS
}

\author{
SITUATION OF THE URBAN AFFORESTATION IN THE MUNICIPALITY OF \\ FREDERICO WESTPHALEN, RS
}

Fernanda Dias dos Santos ${ }^{1}$, Roberta Aparecida Fantinel ${ }^{2}$, Elenice Broetto Weiler ${ }^{3}$, Jussara Cabral Cruz ${ }^{4}$

\begin{abstract}
RESUMO
A arborização urbana em centros urbanos tem contribuído na melhoria da qualidade de vida da população, sob diversos aspectos. O presente trabalho teve como objetivo analisar os aspectos qualitativos e quantitativos da arborização urbana no município de Frederico Westphalen, RS. Foram inventariadas 2.145 árvores, sendo que a espécie Lagerstroemia indica foi a de maior ocorrência, com 458 indivíduos e juntamente com a espécie Ligustrum lucidum respondem por mais de $40 \%$ do total de árvores. Mais de $60 \%$ das espécies foram identificadas como de origem exótica, favorecendo a adaptabilidade de tais espécies. Em relação às redes aéreas, $32 \%$ das árvores interferem nas mesmas, seja em rede de tensão média, baixa, telefônica ou de fibra ótica, e $24 \%$ das árvores possuem o sistema radicular ocasionando danos nas calçadas. Referente a fitossanidade, $78 \%$ das árvores necessitam tratamento, seja emergencial ou preventivo. Quanto ao manejo florestal indicado, todas as árvores analisadas necessitam de interferência, seja controle fitossanitário, poda leve ou pesada, remoção com ou sem reposição, reflexo de falta de planejamento ou planejamento não adequado ao local, constatando-se a necessidade de se desenvolver um plano da (re) arborização do município.
\end{abstract}

Palavras-chave: Planejamento Arbóreo; Espécies Arbóreas; Arborização Urbana; Áreas Verdes.

\section{ABSTRACT}

The urban afforestation in urban centers has contributed to improve the quality of life of the population, in several aspects. The present study had as objective to analyze the qualitative and quantitative aspects of the urban aforestation in the city of Frederico Westphalen, RS. A total of 2,145 trees were inventoried, and the Lagerstroemia indica species was the one with the highest occurrence, with 458 individuals and, together with the species Ligustrum lucidum, account for more than $40 \%$ of the total trees. More than $60 \%$ of the species were identified as of exotic origin, favoring the adaptability of these species. In relation to aerial networks, $32 \%$ of the trees interfere with them, whether in medium, low voltage, telephone or fiber optic networks, and $24 \%$ of the trees have the root system causing damage to the sidewalks. Regarding plant health, $78 \%$ of trees need treatment, whether emergency or preventive. Regarding the indicated forest management, all the analyzed trees need interference, be it phytosanitary control, light or heavy pruning, removal with or without replacement, reflex of lack of planning or planning that is not adequate to the place, noting the need to develop a plan for (re) afforestation of the municipality.

Keywords: Arboreal Planning; Arboreal Species; Urban Afforestation; Green areas.

Recebido em 25.03.2019 e aceito em 18.05.2019

1 Engenheira Florestal. Mestra. Doutoranda em Engenharia Civil na Universidade Federal de Santa Maria. Santa Maria/RS. Email: fernandadiotti@hotmail.com

2 Engenheira Florestal. Mestranda em Engenharia Florestal na Universidade Federal de Santa Maria. Santa Maria/RS. Email: fantinel.ar@gmail.com

3 Engenheira Florestal. Mestra. Doutoranda em Engenharia Florestal na Universidade Federal de Santa Maria. Santa Maria/RS. Email: Elenice.bere@hotmail.com

4.Engenheira Civil. Doutora. Professora Titular na Universidade Federal de Santa Maria. Santa Maria/RS. Email: jussaracruz@gmail.com 


\section{INTRODUÇÃO}

O aumento desordenado da população urbana gera diversos problemas relacionados à composição arbórea nas vias e locais públicos, comprometendo a qualidade de vida dos habitantes e causando impactos no ambiente (JUSTINO et al., 2019), sendo que um dos principais fatores para a redução dos espaços verdes urbanos é o crescimento populacional (ONU, 2015). Devido a esse crescimento populacional desordenado, espaços destinados a arborização urbana foram destinados a outros fins, como por exemplo, habitação e parques industriais, intensificando, desta forma, a arborização de vias públicas, como, canteiros centrais, passeios públicos e faixas de acompanhamento viário.

A arborização de vias públicas além de trazer benefícios, deve apresentar um planejamento, independente do porte da cidade ou do número de habitantes, sendo fundamental para prevenir possíveis problemas futuros. Entre os benefícios oriundos da arborização urbana destaca-se que as árvores podem reduzir a incidência da luz em mais de 90\%, diminuindo a temperatura e a luz direta sobre quem caminha ou se exercita sob elas, influenciando positivamente no conforto térmico das cidades (MARTINI; BIONDI, 2015), ressaltando-se que a qualidade de vida urbana está diretamente atrelada a vários fatores que estão reunidos na infraestrutura, no desenvolvimento econômico e social, e àqueles ligados à questão ambiental.

Diante disso, é de fundamental importância que as cidades, mesmo consideradas pequenas, como é o caso do município de Frederico Westphalen, RS, com população de 31.120 habitantes e PIB per capita de $\mathrm{R} \$ 32.230,60$ (IBGE, 2016), tenham um plano de arborização urbana. Isso porque independentemente do porte da cidade, é muito mais fácil realizar o planejamento e implantação, do que ações de caráter de remediação, dessa forma o planejamento é a melhor ferramenta (WOLCH; BYRNE; NEWELL, 2014), devendo-se escolher a metodologia adequada para cada local e o objetivo, obtendo-se assim informações adequadas sobre a arborização urbana que será utilizada em novos projetos (PAVELSKI, 2014).

Frente a importância da discussão e análise do papel da arborização urbana para melhor aproveitamento dos espaços não edificados das cidades, este estudo objetivou analisar qualitativamente e quantitativamente a arborização urbana do município de Frederico Westphalen, RS por meio da identificação das espécies vegetais arbóreas plantadas nas vias públicas (passeios públicos, canteiros centrais e faixas de acompanhamento viário) e áreas verdes públicas.

\section{MATERIAL E MÉTODOS}

O presente estudo foi realizado no município de Frederico Westphalen, no Estado do Rio Grande do Sul, Brasil, localizado nas coordenadas $27^{\circ} 21^{\prime} 33^{\prime \prime}$ de latitude sul e $53^{\circ} 23^{\prime} 40^{\prime \prime}$ de 
longitude oeste, com altitude de 522 metros acima do nível do mar e território de 264,5 km² (Figura 1). O clima da região é subtropical, onde a temperatura média anual varia de $20-23^{\circ} \mathrm{C}$. A precipitação média anual geralmente é entre 1.700 e 1.900 mm, bem distribuídos ao longo do ano (ROSSATO, 2011).

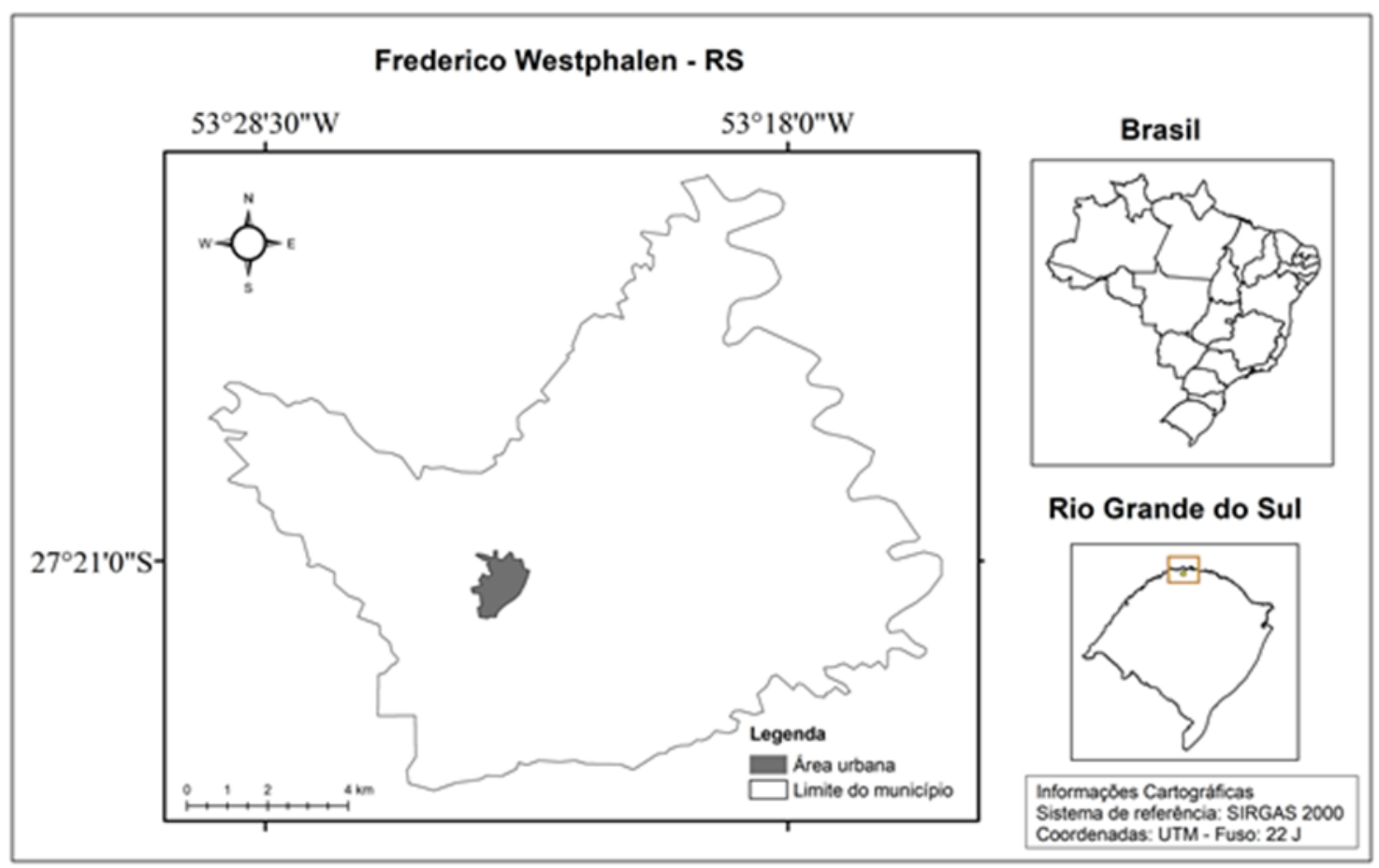

Figura 1. Localização do município de Frederico Westphalen, RS.

Figure 1. Location of the municipality of Frederico Westphalen, RS.

O método adotado para o levantamento qualitativo e quantitativo foi o censo total, sendo contabilizados e identificados todos os indivíduos de porte arbóreo e não arbóreo de acordo com Lorenzi (1992) e Flora do Brasil (2019). Quanto à identificação da espécie foi realizado in loco, considerando o nome popular, nome científico e origem (nativa ou exótica). As espécies não identificadas foram coletadas e encaminhadas ao Herbário do Departamento de Ciências Agrárias da Universidade Federal de Santa Maria, bem como verificados e conferidos o nome científico das espécies, através da literatura específica de acordo com Lorenzi (1992) e a Lista de Espécies da Flora do Brasil (2019).

Foi realizado censo de todas as espécies arbóreas vivas com CAP (circunferência acima do peito) mínimo $>5 \mathrm{~cm}$ presentes nas vias públicas da área urbana utilizando régua altimétrica de 5 metros e fita métrica.

Referente ao aspecto qualitativo, considerou-se informações referentes ao aspecto de fitossanidade, sendo: boa, satisfatória e ruim. Avaliou-se também o sistema radicular quanto: profundo sem danos, profundo com danos, superficial sem danos e superficial com danos. Já para redes aéreas, levou-se em consideração a interferência nas redes de tensão média, 
interferências nas redes de tensão baixa, interferência nas redes telefônicas e de fibra ótica e não interferência nas redes aéreas. Para a determinação da necessidade do manejo arbóreo, ponderou-se: controle fitossanitário, poda leve, poda pesada, remoção sem reposição, remoção com reposição.

A frequência relativa das espécies foi calculada segundo Schneider e Finger (2000), no qual a frequência indica como as espécies estão distribuídas sobre a área amostrada, sendo determinada pela seguinte fórmula:

$$
F R=(n i / N) * 100
$$

Sendo:

$\mathrm{FR}=$ Frequência relativa;

ni = Número de indivíduos da espécie i;

$\mathrm{N}=$ Número total de indivíduos.

\section{RESULTADOS E DISCUSSÃO}

O levantamento quantitativo resultou a presença de 2.145 árvores que estão distribuídas em 51 espécies nas vias do município de Frederico Westphalen, RS, sendo que apenas 38\% das espécies encontradas na arborização urbana do município é nativa. Isto encontra forte correlação com a história do paisagismo brasileiro (CHAMAS e MATTHES, 2000), onde a maioria das espécies utilizadas na arborização urbana são exóticas. Kiyuna et al. (2002) e Marques e Filho (2003) afirmaram que a diversidade e a amplitude de climas e solos no nosso país permitem cultivos de uma vasta gama de espécies de plantas ornamentais, incluindo tanto as nativas como as exóticas, cabendo aos técnicos responsáveis a decisão referente as espécies que devem ser introduzidas em determinado ambiente.

As famílias mais abundantes em número de espécies foram Myrtaceae (7 espécies), seguida por Bignoniaceae (6 espécies) e Fabaceae (5 espécies), totalizando 18,2\% dos exemplares.

Na Tabela 1 estão apresentadas as espécies, a família a qual pertencem, assim como o número de indivíduos, a frequência e a origem.

Tabela 1. Espécies presentes na arborização urbana no município de Frederico Westphalen, RS Table 1. Species present in urban afforestation in the municipality of Frederico Westphalen, RS

\begin{tabular}{lllccc}
\hline ESPÉCIE & NOME POPULAR & FAMÍLIA & N & FR (\%) & ORIGEM \\
\hline Lagerstroemia indica & Extremosa & Lythraceae & 458 & 21,35 & Exótica \\
Ligustrum lucidum & Ligustro & Oleaceae & 412 & 19,21 & Exótica \\
Cinnamomum zeylanicum & Canela-doce & Lauraceae & 242 & 11,28 & Exótica \\
Ficus benjamina & Figueira-benjamim & Moraceae & 164 & 7,65 & Exótica \\
Cupressus sp. & Cipreste & Cupressaceae & 85 & 3,96 & Exótica \\
Hibiscus rosa-sinensis & Hibisco & Malvaceae & 68 & 3,17 & Exótica \\
\hline
\end{tabular}




\begin{tabular}{|c|c|c|c|c|c|}
\hline ESPÉCIE & NOME POPULAR & FAMÍLIA & $\mathbf{N}$ & FR (\%) & ORIGEM \\
\hline Mangifera indica & Mangueira & Anacardiaceae & 57 & 2,66 & Exótica \\
\hline Caesalpinia peltophoroides & Sibipiruna & Fabaceae & 55 & 2,56 & Nativa \\
\hline Eugenia uniflora & Pitangueira & Myrtaceae & 51 & 2,38 & Nativa \\
\hline Ficus auriculata & Figueira-vermelha & Moraceae & 48 & 2,24 & Exótica \\
\hline Syzygium jambolanum & Jambolão & Myrtaceae & 48 & 2,24 & Exótica \\
\hline Psidium guajava & Goiabeira & Myrtaceae & 45 & 2,10 & Nativa \\
\hline Syagrus romanzoffiana & Jerivá & Arecaceae & 38 & 1,77 & Nativa \\
\hline Handroanthus avellanedae & Ipê-rosa & Bignoniaceae & 29 & 1,35 & Nativa \\
\hline Archontophoenix cunninghamiana & Palmeira-real & Arecaceae & 28 & 1,31 & Nativa \\
\hline Eugenia involucrata & Cerejeira & Myrtaceae & 24 & 1,12 & Nativa \\
\hline Brunfelsia uniflora & Manacá-de-cheiro & Solanaceae & 23 & 1,07 & Nativa \\
\hline Jacaranda mimosifolia & Jacarandá-mimosa & Bignoniaceae & 23 & 1,07 & Nativa \\
\hline Inga marginata & Ingá & Fabaceae & 20 & 0,93 & Nativa \\
\hline Citrus sp. & Laranjeira & Rutaceae & 17 & 0,79 & Exótica \\
\hline Myrcianthes pungens & Guabiju & Myrtaceae & 16 & 0,75 & Nativa \\
\hline Handroanthus chrysotricus & Ipê-amarelo & Bignoniaceae & 16 & 0,75 & Nativa \\
\hline Myrcianthes pungens & Guabiju & Myrtaceae & 16 & 0,75 & Nativa \\
\hline Butia eriosphata & Butiá & Arecaceae & 14 & 0,65 & Exótica \\
\hline Cordia trichotoma & Louro-pardo & Boraginaceae & 14 & 0,65 & Nativa \\
\hline Eriobotrya japonica & Nêspera & Rosaceae & 14 & 0,65 & Exótica \\
\hline Spathodea campanulata & Tulipeira & Bignoniaceae & 12 & 0,56 & Exótica \\
\hline Spathopea nilotica & Árvore-de-bisnagas & Bignoniaceae & 12 & 0,56 & Exótica \\
\hline Duranta erecta & Violeteira & Verbenaceae & 10 & 0,47 & Exótica \\
\hline Delonix regia & Flamboyant & Fabaceae & 9 & 0,42 & Exótica \\
\hline Tipuana tipu & Tipuana & Fabaceae & 9 & 0,42 & Nativa \\
\hline Cordyline terminalis & Dracena-vermelha & Asparagaceae & 8 & 0,37 & Exótica \\
\hline Acer palmatum & Bôrdo-japonês & Sapindaceae & 6 & 0,28 & Exótica \\
\hline Diospyrus kaki & Caquizeiro & Ebenaceae & 6 & 0,28 & Exótica \\
\hline Pyrus communis & Pereira & Rosaceae & 6 & 0,28 & Exótica \\
\hline Buxus sempervirens & Árvore-da-caixa & Buxaceae & 5 & 0,23 & Exótica \\
\hline Scheffera actinophylla & Cheflera & Araliaceae & 5 & 0,23 & Exótica \\
\hline Schinus molle & Salso & Anacardiaceae & 5 & 0,23 & Nativa \\
\hline Annona neosalicifolia & Araticum & Annonaceae & 4 & 0,19 & Exótica \\
\hline Nerium oleander & Oleandro & Apocynaceae & 4 & 0,19 & Exótica \\
\hline Ilex paraguariensis & Erva-mate & Aquifoliaceae & 3 & 0,14 & Nativa \\
\hline Jacaranda micrantha & Caroba-rosa & Bignoniaceae & 3 & 0,14 & Nativa \\
\hline Jasminum sambac & Jasmin-árabe & Oleaceae & 2 & 0,09 & Exótica \\
\hline Peltophorum dubium & Canafístula & Fabaceae & 2 & 0,09 & Nativa \\
\hline Persea americana & Abacateiro & Lauraceae & 2 & 0,09 & Exótica \\
\hline Populus nigra & Álamo-negro & Salicaceae & 2 & 0,09 & Exótica \\
\hline Allophylu adulis & Chal-chal & Sapindaceae & 1 & 0,05 & Nativa \\
\hline Camellia japonica & Camélia & Theaceae & 1 & 0,05 & Exótica \\
\hline Myrciaria cauliflora & Jaboticabeira & Myrtaceae & 1 & 0,05 & Nativa \\
\hline Populus alba & Álamo-branco & Salicaceae & 1 & 0,05 & Exótica \\
\hline Rosa sinensis & Hibisco-da-china & Malvaceae & 1 & 0,05 & Exótica \\
\hline TOTAL DE INDIVÍDUOS & & & 2145 & 100 & \\
\hline
\end{tabular}


Dentre as espécies levantadas, observa-se que algumas apresentam maior frequência, destacando-se Lagerstroemia indica, com 458 exemplares, seguida por Ligustrum lucidum, com 412 exemplares, representando 21,4 e 19,2\%, respectivamente, confrontando o estudo de Kenney, Van Wassenaer e Satel (2011), em que, para o adequado planejamento da arborização, cada espécie não deve ultrapassar $15 \%$ do total de indivíduos arbóreos na área urbana. Este estudo corrobora com Manfrin et al. (2019), que afirma a predominância de poucas espécies na arborização de cidades brasileiras, como por exemplo, o trabalho desenvolvido por Agência Municipal de Meio Ambiente (2008), na cidade de Goiânia, onde 15 espécies representaram $72,2 \%$ da arborização da cidade.

Conforme Haas et al. (2011), um número alto de espécies na arborização viária de um município é um fator positivo, pois reduz os riscos de transmissão de doenças e infestação por patógenos, que pode acontecer mais facilmente quando se tem um baixo número de espécies.

Dentre as espécies exóticas de maior ocorrência, destaca-se Ligustrum lucidum (Figura 2), árvore de porte grande, não recomendada para arborização urbana por não contribuir para a biodiversidade do local e ainda possuir um sistema radicular agressivo e forte, podendo gerar sérios danos às vias públicas impedindo a passagem de pedestres (KRAMER; KRUPEK, 2012). Gonçalves, Coral e Siqueira (2017) mencionam que Ligustrum lucidum foi avaliada como a espécie mais frequente em áreas verdes e espaços públicos do centro do município de lbitinga no Estado de São Paulo. Conforme os mesmos autores, a espécie é amplamente utilizada na arborização urbana, principalmente nas regiões Sul e Sudeste do Brasil.

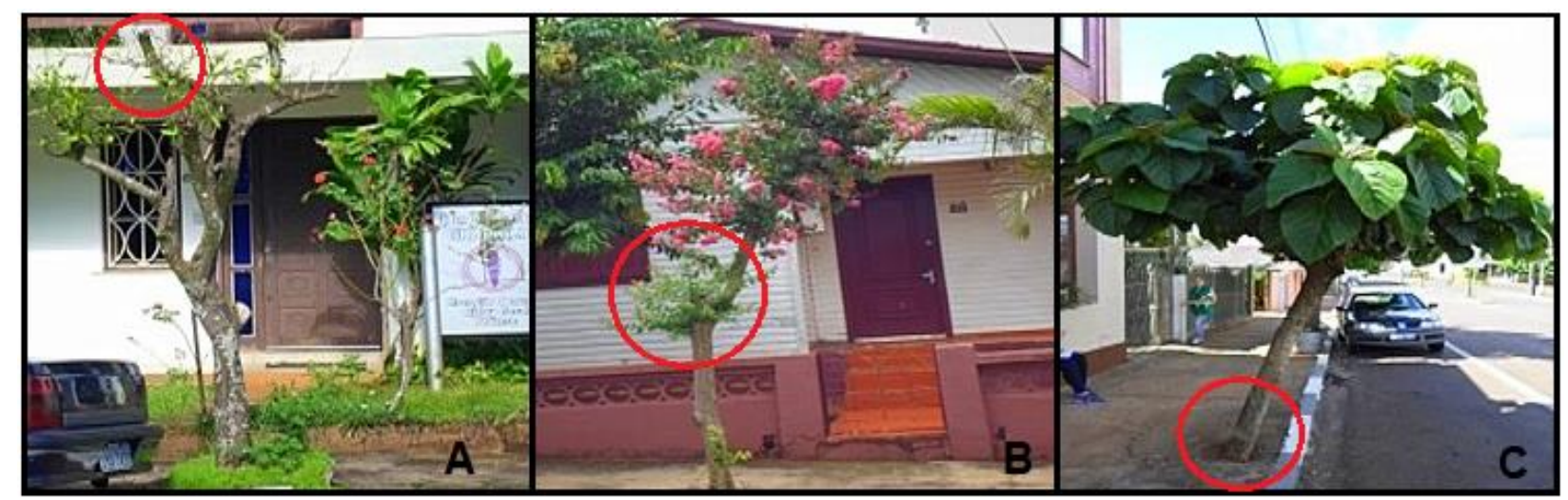

Figura 2. Imagens A e B) Poda drástica realizada pela população na arborização urbana e a imagem C) Conflito da espécie com a calçada (passeio)

Figure 2. Images $A$ and B) Drastic pruning done by the population in the urban arborization and the image C) Conflict of the species with the sidewalk (tour)

Apesar de, a maioria (68\%) dos exemplares não interferirem com as redes aéreas (Figura 3), ainda assim um número significativo está em conflito com as mesmas, reflexo, muitas vezes, do rápido crescimento das cidades, dificultando a execução do planejamento adequado de ocupação do solo, o que há muito tempo já interfere na qualidade de vida do homem que 
habita a cidade (CABRAL, 2013). Martelli (2017) diz que arborizar não é apenas plantar mudas, ao acaso, na cidade, visto que as árvores do perímetro urbano são constantemente ameaçadas pelo descuido da população e do poder público e pela instalação ou mesmo localização dos equipamentos destinados ao atendimento das necessidades públicas, como redes elétricas, de água e esgoto.

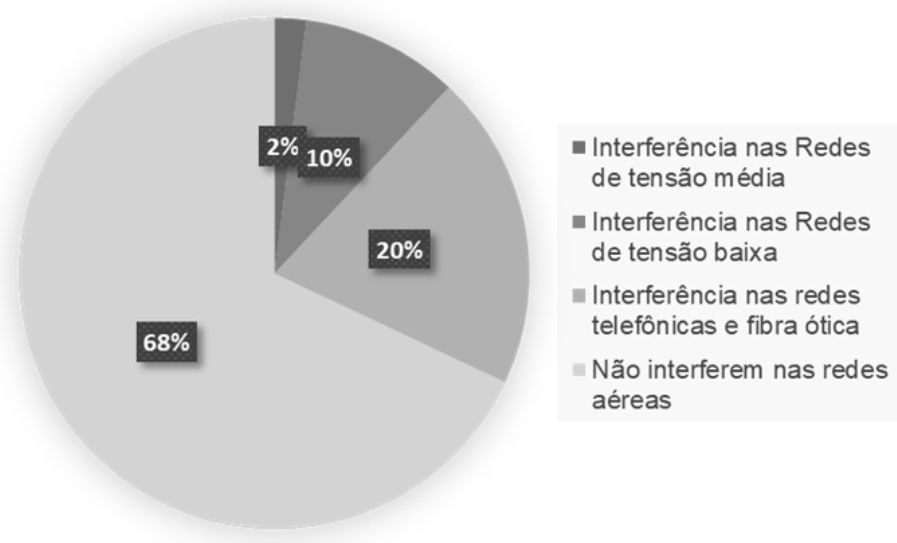

Figura 3. Interferência da arborização urbana do município de Frederico Westphalen, RS, com as redes aéreas

Figure 3. Interference of the urban afforestation of the city of Frederico Westphalen, RS, with the aerial networks

Referente aos danos causados pelo sistema radicular das espécies utilizadas, 44\% estão ocasionando danos nas calçadas, ou seja, em caso de planejamento da arborização, praticamente metade das espécies deveriam ser substituídas, considerando-se tal fator (Figura 4). Raber e Rebelato (2010) afirmam que a falta de área livre, capaz de permitir a infiltração de águas e nutrientes para a planta, provoca mau desenvolvimento das mesmas, e a utilização de espécies com sistema radicular pouco profundo numa área pequena, pode danificar a calçada, devido a pressão exercida pelas raízes.

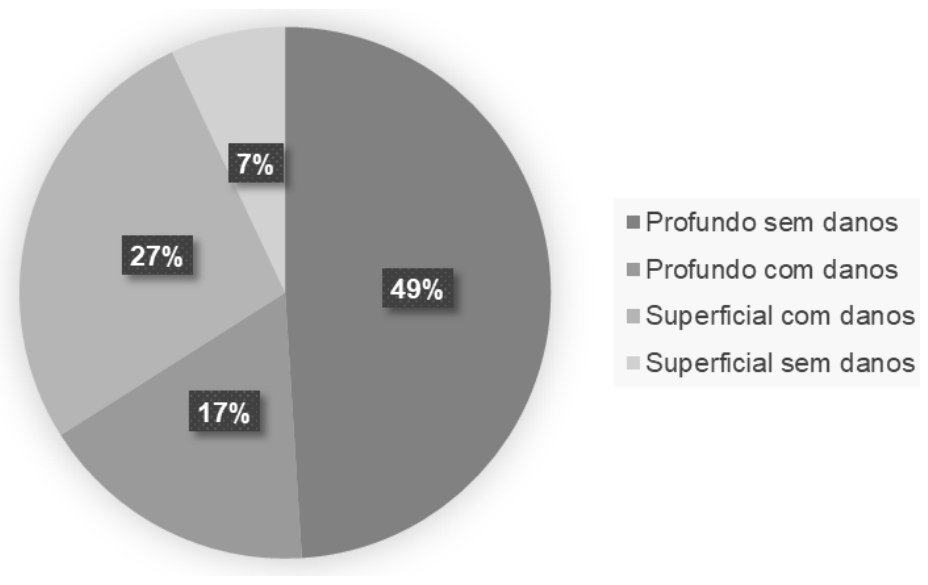

Figura 4. Profundidade do sistema radicular da arborização urbana do município de Frederico Westphalen, RS, nas calçadas

Figure 4. Root system's depth of the urban afforestation of Frederico Westphalen, RS, on the sidewalks 
Das espécies utilizadas na arborização urbana no município de Frederico Westphalen, 150 exemplares necessitam de tratamento emergencial devido ao ataque de pragas e doenças e 1.524 exemplares demandam de tratamento preventivo, principalmente por estarem em risco de contaminação pela proximidade com espécies altamente afetadas (Figura 5). A diversificação das espécies é fundamental para contribuir com melhoria da estética do ambiente e redução de ataques de pragas, sendo que os riscos ficam mais distribuídos, evitando que a arborização de ruas de uma cidade seja dizimada por um surto de pragas e doenças (ALBERTIN et al., 2011).

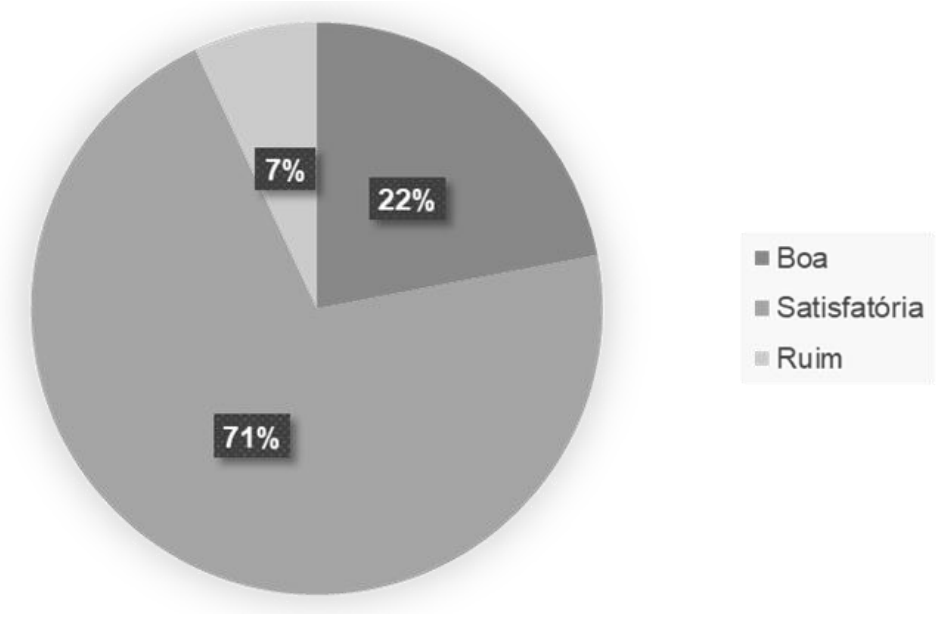

Figura 5. Fitossanidade das espécies levantadas na arborização urbana do município de Frederico Westphalen, RS

Figure 5. Phytosanitary state of the species inventoried in the urban afforestation of Frederico Westphalen, RS

Quanto ao manejo florestal, a arborização urbana em questão, necessita, na sua totalidade, de algum tipo de interferência, seja controle fitossanitário, poda ou remoção do exemplar (Figura 6), configurando um ajuste no planejamento da escolha, distribuição e manejo das espécies utilizadas.

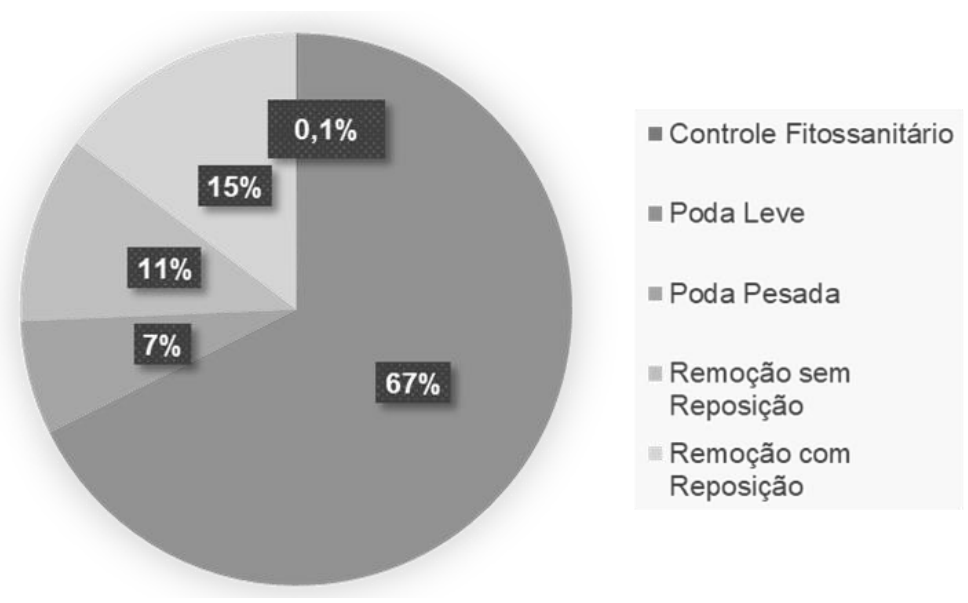

Figura 6. Manejo florestal indicado para a arborização urbana do município de Frederico Westphalen, RS Figure 6. Indicated forest management for the urban afforestation of Frederico Westphalen, RS 
Um aspecto relevante referente ao plantio de árvores requer cuidados especiais, uma vez que, a escolha de espécies e locais inadequados poderá gerar diversos conflitos, entre eles cita-se a poda drástica e o corte raso, gerando à prefeitura onerosos custos com manejo, que via de regra ocorrem em caráter emergencial em vez de preventivo (PIRES et al., 2010).

\section{CONCLUSÕES}

Pela análise quali-quantitativa realizada neste estudo, concluiu-se que há deficiência no planejamento da arborização urbana no município de Frederico Westphalen, $\mathrm{RS}$, tais como: falta de manejo adequado na poda de condução, manejo fitossanitário, implantação de espécies com porte adequado ao seu desenvolvimento, tanto para sistema radicular quanto à copa e a utilização de poucas espécies, visto que algumas ultrapassaram o percentual de $15 \%$, indicado pelo Plano de Arborização Urbana. Sendo assim, constatou-se a necessidade de se desenvolver um planejamento da (re) arborização do município.

\section{REFERÊNCIAS}

AGÊNCIA MUNICIPAL DE MEIO AMBIENTE (Goiânia). Arborização Urbana de Goiânia: 2008. 134 p. Disponível em: http://www.goiania.go.gov.br/download/amma/relatorio_Plano_Diretor. pdf. Acesso em: 20 fev 2019.

ALBERTIN, R. M., ANGELIS, R. D., ANGELIS NETO, G. D., ANGELIS, B. Diagnóstico qualiquantitativo da arborização viária de Nova Esperança, Paraná, Brasil. Revista da Sociedade Brasileira de Arborização Urbana, v. 6, n. 3, p. 128-148, 2011.

CABRAL, P.I.D. Arborização urbana: problemas e benefícios. Especialize on-line, Goiania, v. 1, n. 6, p. $15,2013$.

CHAMAS, C. C., MATTHES, L. A. F. Método para levantamento de espécies nativas com potencial ornamental. Ornamental Horticulture, Campinas, v. 6, n. 1, p.53-63, 2000.

GONÇALVES, W. B.; CORAL, D. J.; SIQUEIRA, M. V. B. M. Caracterização da arborização urbana no bairro centro do município de Ibitinga/SP. Revista da Sociedade Brasileira de Arborização Urbana, Piracicaba, v. 12, n. 3, p. 66-79, 2017.

HAAS, S. E.; HOOTEN, M. B.; RIZZO, D. M.; MEENTEMEYER, R. K. Forest species diversity reduces disease risk in a generalist plant pathogen invasion. Ecology Letters, Oxford, v. 14, n. 11, p. 1108-1116, 2011.

IBGE - INSTITUTO BRASILEIRO DE GEOGRAFIA E ESTATíSTICA, 2016. Resultado dos Dados Preliminares do Censo - 2016. Disponível em https://www.ibge.gov.br/estatisticas/ sociais/populacao. Acesso em 10 de janeiro de 2019.

JUSTINO, S. T. P., MORAIS, Y. Y. G. A., DE ALMEIDA NASCIMENTO, A. K., SOUTO, P. C. COMPOSIÇÃO E GEORREFERENCIAMENTO DA ARBORIZAÇÃO URBANA NO DISTRITO DE SANTA GERTRUDES, EM PATOS-PB. Revista da Sociedade Brasileira de Arborização Urbana, v. 13, n. 3, p. 24-35, 2019. 
KENNEY, W. A.; VAN WASSENAER, P. J. E.; SATEL, A. L. Criteria and indicator for strategic urban forest planning and management. Arboriculture \& Urban Forestry, Kenney, v. 37, n. 3, p. 108-117, 2011.

KIYUNA I, FRANCISCO V.L.F.S, COELHO P.J, CASER D.V, ASSUMPÇÃO R. ÂNGELO JÁ. A floricultura brasileira no início do século XXI: o perfil do produtor. Informações Econômicas, São Paulo, v. 34, n.4, p.14-32, 2004.

KRAMER J. A.; KRUPEK R. A. Caracterização florística e ecológica da arborização de praças públicas do município de Guarapuava, PR. Revista Árvore, Viçosa, v.36, n.4, p.647-658, 2012.

LISTA DE ESPÉCIES DA FLORA DO BRASIL. Jardim Botânico do Rio de Janeiro. Disponível em: <http://floradobrasil.jbrj.gov.br/>. Acesso em: 25 fev. 2019.

LORENZI, H. Árvores brasileiras: manual de identificação e cultivo de plantas arbóreas nativas do Brasil. Nova Odessa: Plantarum, 1992. 385 p.

MANFRIN, J., DA SILVA ESCHER, M. A., DE CASTRO, G. M., ALEIXO, V., PETRY, A. I., BUENO, T. DIAGNÓSTICO DA ARBORIZAÇÃO URBANA DO MUNICÍPIO DE OURO VERDE DO OESTE, PARANÁ. Revista da Sociedade Brasileira de Arborização Urbana, v. 13, n. 3, p. 49-61, 2019.

MARQUES R.W.C.; FILHO J.V. Avaliação da sazonalidade do mercado de flores e plantas ornamentais do Estado de São Paulo. Ornamental Horticulture, Campinas, v.9,p.143-160, 2003.

MARTELLI, A.; DELBIM, L. R. Arborização urbana: percepção dos acadêmicos de Educação Física da Faculdade FMG Mogi Guaçu. Journal of Health Sciences, v.19, n.3, p.154-159, 2017.

MARTINI, A.; BIONDI, D. Microclima e conforto térmico de um fragmento de floresta urbana em Curitiba, PR. Revista Floresta e Ambiente, Rio de Janeiro, v. 22, p. 182-193, 2015.

ORGANIZAÇÃO DAS NAÇÕES UNIDAS - ONU. Department of Economic and Social Affairs, Population Division. World Urbanization Prospects: The 2014 Revision. New York, 2015. Disponível em: https://esa.un.org/unpd/wup/Publications/Files/WUP2014-Report.pdf>. Acesso em: 11 fev. 2019.

PAVELSKI, L. G. Análise quali-quantitativa da arborização existente no Parque Central José Rossi Adami, no município de Caçador, SC. 2014. 57 p. Dissertação (Mestrado em Gestão Florestal) -Universidade Federal do Paraná, Curitiba -PR, 2014.

PIRES, N. A. M. T., MELO, M. D. S., OLIVEIRA, D. D., SANTOS, S. X. A arborização urbana do município de Goiandira/GO-caracterização qualiquantitativa e propostas de manejo. Revista da Sociedade Brasileira de Arborização Urbana, v. 5, n. 3, p. 185-205, 2010.

RABER, A. P., REBELATO, G. S. Arborização viária do município de Colorado, RS-Brasil: análise quali-quantitativa. Revista da Sociedade Brasileira de Arborização Urbana, v. 5, n. 1, p. 18399, 2010.

ROSSATO, M. S. 2011, 253 f. Os climas do Rio Grande do Sul: variabilidade, tendências e tipologia. Tese (Doutorado em Geografia). Porto Alegre: Universidade Federal do Rio Grande do Sul. 2011.

SCHNEIDER, P. R.; FINGER, C. A. G. Manejo sustentado de florestas inequiâneas heterogêneas. Santa Maria: UFSM, 2000. 195p.

WOLCH, J. R.; BYRNE, J.; NEWELL, J. P. Urban green apace, public health, and environmental justice: The challenge of making cities 'just green enough'. Landscape and Urban Planning, Nova York, v. 125, p. 234-244, 2014. 